\title{
The demography of education in Brazil: inequality of educational opportunities based on Grade Progression Probability (1986-2008) ${ }^{1}$
}

\author{
Eduardo Luiz Gonçalves Rios-Neto and Raquel Rangel de Meireles \\ Guimarães *
}

\begin{abstract}
This article shows evidence regarding the educational attainment and inequality of educational opportunities in Brazil based on the grade progression probability method (GPP) between the years 1981 and 2008. We describe some stylised facts about the educational trajectory in Brazil, then we test two hypothesis suggested by Mare $(1979,1980)$. The first hypothesis states that the effect of social origins decreases along the educational trajectory. The second states that the educational expansion between two periods would reduce the inequality of educational opportunities in a given grade. Results show an increase in grade probability in nearly all grades, but this trend is most striking in the earlier stages. Educational stratification results show that Mare's first hypothesis could not be corroborated. The second hypothesis was partly confirmed. We found a decline during the period analysed on the effect of household head's education on grade progression at the earlier transitions. Furthermore, the selectivity pattern seemed to be transferred to later grade transitions.
\end{abstract}

\footnotetext{
This article is based on a keynote address at the Education and Demography International Conference, organised by Vienna Institute of Demography (VID) and International Institute for Applied Systems Analysis (IIASA), Vienna, November 30th - December 1st, 2009. The research activities were conducted at Observatório de Educação, sponsored by CAPES and INEP at the Ministry of Education.

* Eduardo Luiz Gonçalves Rios-Neto (correspondence author), Demography Department and CEDEPLAR-Center for Regional Development and Planning of the Universidade Federal de Minas Gerais (UFMG), Av. Antônio Carlos 6627, Belo Horizonte, MG/CEP: 31270-901, Brazil. Email: eduardo@cedeplar.ufmg.br

Raquel Rangel de Meireles Guimarães, CEDEPLAR-Center for Regional Development and Planning of the Universidade Federal de Minas Gerais (UFMG), Belo Horizonte, Brazil.
}

DOI: 10.1553/populationyearbook2010s283 


\section{Introduction}

The expansion of a population's education attainment has been a common feature in developed societies. Education is also considered a key factor for economic growth and development in nations that are not considered fully developed. The provision of public education and its expansion to universal coverage contributed to the decline in the costs of education in developed societies. Nevertheless, the merit selection hypothesis in sociology is questioned by a vast range of alternative formulations in the field of social stratification (Shavit and Blossfeld 1993; Jenks and Tach 2006; Shavit et al. 2007).

In a historical context Brazil lagged behind in the education revolution, even compared to countries in the Latin American region. Contrary to what occurred in several other countries, social expenditure in Brazil took place first in social security and infrastructure, while expenditures in public education were historically neglected. Universal coverage in education only took place in Brazil during the last decade of the 20th century, while other countries such as Argentina had their first wave of education revolution during the late 1800s.

The Brazilian shift towards universal coverage in primary education during the 1990s contributed to an increase in education attainment, measured by average schooling or completed years of education. Two exercises will be performed in the Brazilian context, a country with late education expansion accompanied by a high level of education stratification and income inequality. A first exercise is established by the analysis of grade progression trends for every grade and the performance of grade decomposition in the final average schooling attained, in order to determine which grades are more important in the gains obtained in education attainment. A second exercise aims to discuss two hypotheses of the social stratification debate in the Brazilian context.

This article is organised into four parts. In the first part we present some stylised facts associated with recent Brazilian education expansion. The second part deals with the definition of grade progression probability and the presentation of recent trends of this indicator in the Brazilian context. The third part extends some concepts associated with grade progression probability and performs a decomposition exercise. The fourth part deals with the theoretical, methodological and empirical discussion of two hypotheses of social stratification in school transition models applied to the Brazilian case.

\section{Stylised facts about Brazilian education expansion}

Figure 1 shows the evolution of average schooling calculated for the Brazilian population aged 7-25 between 1986 and 2008. Average schooling increased from four to six years of study in a 22-year time span. The historical path of the increase of education attainment in Brazil through time is around one year of 
schooling per decade, starting during the post-World War II period. This path was accelerated in the second half of the 1990s, when a school coverage expansion took place. In 1993, an education fund (FUNDEF) was created along with a program aimed at enrolling all children in school. Comparing Brazilian education attainment with the figures in some developed and developing countries, average schooling is well below the United States (12.5 years), United Kingdom (9.4 years) and Argentina (8.8 years). In the Latin American region Brazil is ranked low compared with its position in per capita GDP (Barro and Lee 2001).

A great deal of the Brazilian process of social stratification can be seen in Figure 2, where the average schooling of individuals through time is plotted by the education of the head of the household. Not only do the average years of schooling increase monotonically with the head of the household's education, but there is also no sign of convergence through time when education attainment increases in all levels. It seems that the pattern of education expansion that takes place in Brazil is one that does not affect the engine of social stratification

Another way to see the role of inequality on average schooling differences is presented in Figure 3. Individuals are separated by three thirds of household per capita income. Not only is educational attainment monotonically affected by household per capita income, but also the distance among the curves remains constant through time.

\section{Figure 1:}

Average years of schooling in Brazil, 1981-2008

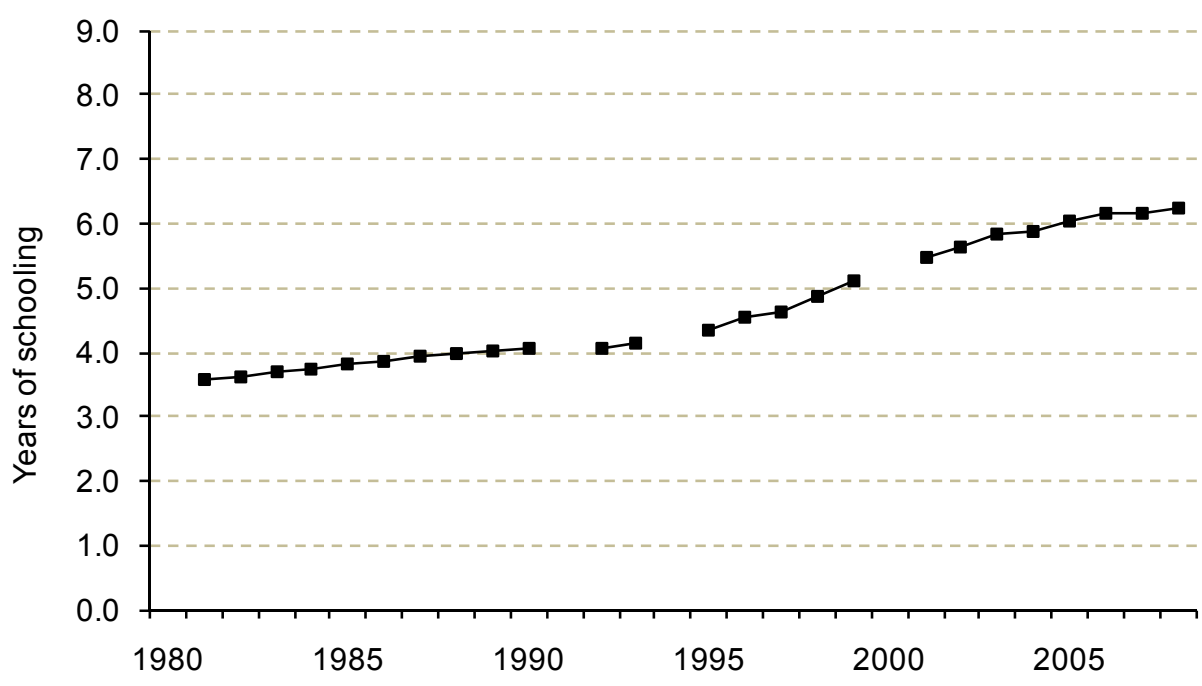

Source: PNAD 1981 and 2008 
Figure 2:

Average years of schooling by head's education in Brazil, 1986-2008

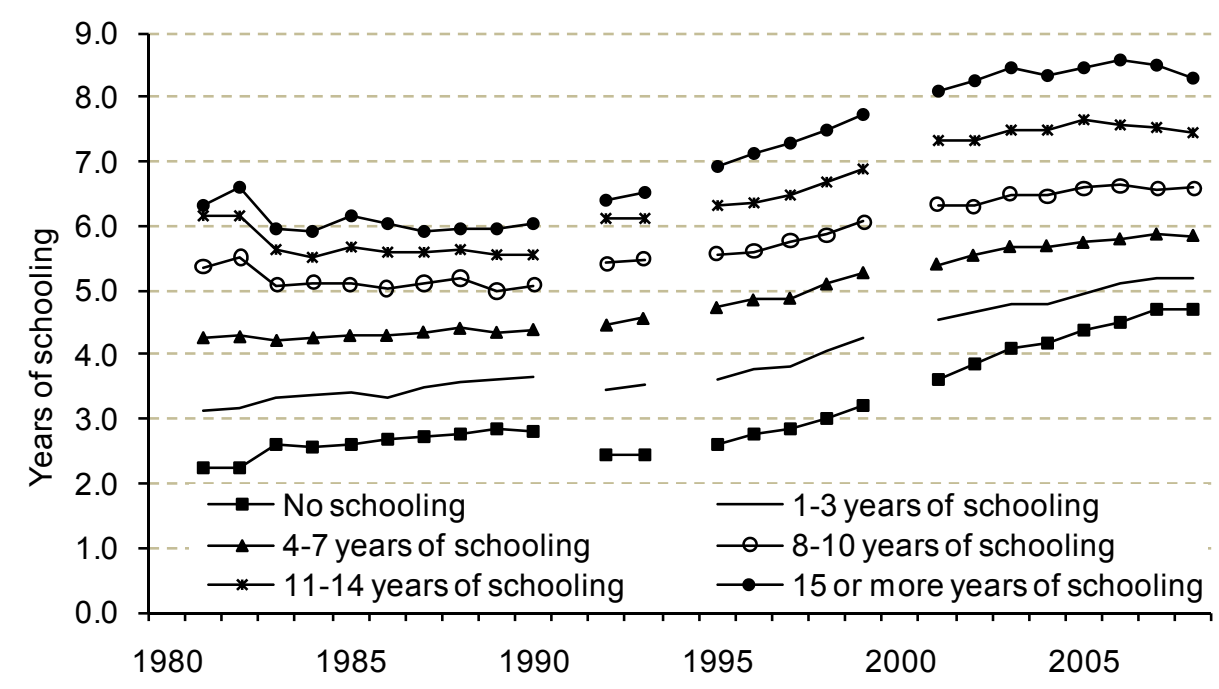

Source: PNAD 1981 and 2008

\section{Figure 3:}

Average years of schooling by selected quantiles of real family income per head in Brazil, 1981-2008

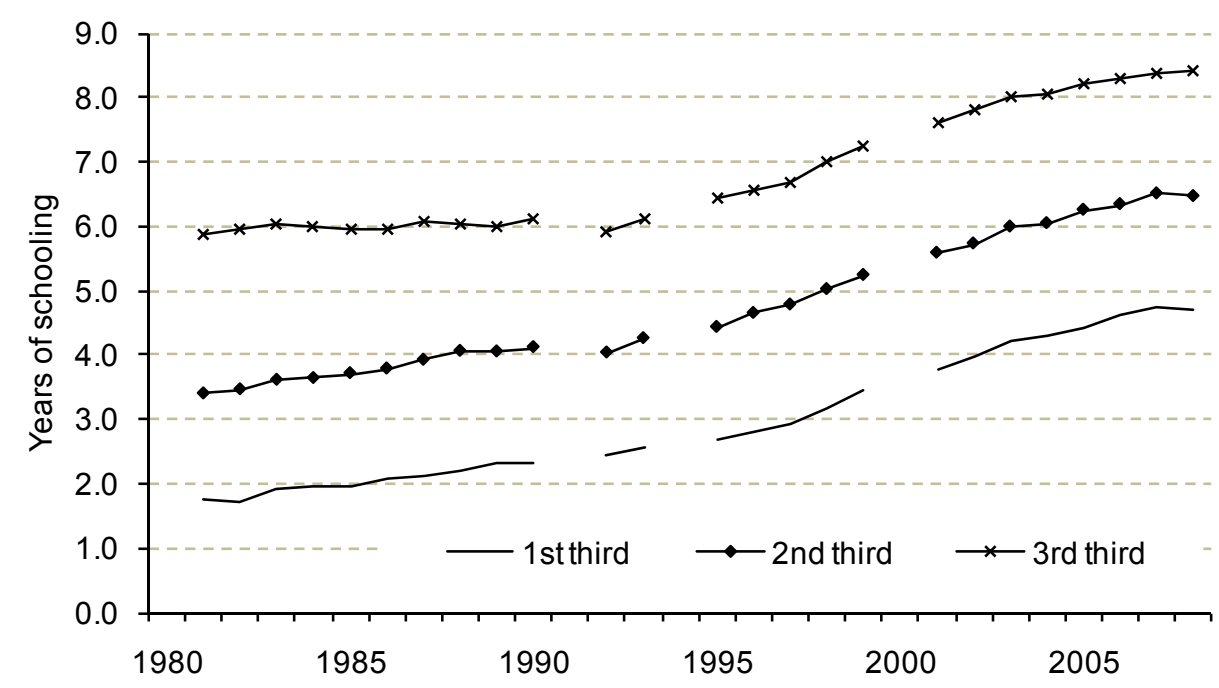

Source: PNAD 1981 and 2008 


\section{The Grade Progression Probability (GPP) method and stylised facts}

This section is based on formulations previously developed in Rios-Neto (2004). The basic motivation was to build a grade progression model based on an analogy with the demographic concept of parity progression ratio, as well as to make an analogy between average schooling (education attainment) and total fertility rate ${ }^{2}$ as indicators derived from this progression. The grade progression probability is a concept similar to the grade progression rate suggested by Mare $(1979,1980)$. The main difference between our formulation and Mare's is that the latter is conditioned on school attendance in the subsequent grade after the progression, while ours is a cohort (actual or synthetic) measure based on the progression from a grade previously concluded to the following grade also completed. By conditioning on school attendance, Mare's measurement is a period measure.

The uniqueness of the GPP method is that education is composed of an accumulation of several progressions. For example, consider an individual who has two years of schooling. From the viewpoint of GPP, this individual has progressed equally to the first grade, as well as to the second grade. Therefore, this individual will factor into the sample for the first school transition as well as into the sample for the second transition. In the Grade Progression Rate framework, as proposed by Mare, all individuals who attend or have completed a certain series are considered, conditional on being enrolled in the subsequent grade.

Thus, GPP is not a period measure. It includes people not attending school. It includes everyone having completed grade ' $\mathrm{k}$ ' in a cohort, since they are also at risk of eventually progressing to grade ' $\mathrm{k}+1$ '. This is very important in the context of developing countries, where grade progression probability is affected not only by promotion of grades, but also by school coverage and age at school entry. Another advantage of GPP is that it leads to the calculation of average schooling, as will be demonstrated below.

As in the parity progression rate in fertility, the GPP is a conditional progression. Average schooling is analogous to total fertility rate. GPP is better suited to cohort application when the school trajectory of a cohort is completed but it can also be applied to a period context, with the application of a synthetic cohort notion (Rios-Neto 2004).

A good reference to parity progression ratio can be found in Pressat (1972) and Preston et al. (2001). 
Given a real or synthetic cohort, grade progression probability from grade $\mathrm{k}$ to grade $\mathrm{k}+1$ is denoted by $e_{\mathrm{k}}$, obtained from the equation below:

$$
e_{k}=\frac{P_{k+1}}{P_{k}}
$$

where $\mathrm{P}_{\mathrm{k}+1}$ is the number of people in the cohort that concluded grade $k+1$ and $\mathrm{P}_{\mathrm{k}}$ is the number of people in the cohort that concluded grade $k$.

Data for calculating GPP was obtained from a series of national household surveys named PNAD, conducted by the Brazilian Census Bureau (IBGE). For each period of analysis, individuals classified as sons and daughters, aged between seven and 25 years, were collected from households.

Figure 4 presents the GPP for crucial grades in the grade progression flow $\left(\mathrm{e}_{0}\right.$, $\mathrm{e}_{4}, \mathrm{e}_{8}, \mathrm{e}_{11}$ ), as it will be demonstrated below. Considering the level of the curves, there is a monotonic decline in the level of grade progression from $\mathrm{k}=0$ (progression to grade 1) until $\mathrm{k}=11$ (progression to the first year of college education). The time component of each grade progression indicates an increase in $\mathrm{e}_{0}$ and $\mathrm{e}_{4}$ during the $1990 \mathrm{~s}$. This is partially explained by an increase in educational coverage observed during this period, although an increase was also observed in grade promotion through education policies of automatic promotion at grade 1, a strategy adopted by some school systems in Brazil. Historically, both $\mathrm{e}_{0}$ and $\mathrm{e}_{4}$ have been the major bottlenecks in Brazilian education attainment as demonstrated below.

The fact should be stressed that $\mathrm{e}_{0}$ reached almost 1 over time. There is also an increase of twenty percentage points in $\mathrm{e}_{4}$, as well as an increase in $\mathrm{e}_{8}$ during the period studied, although the proportion that concludes the first year of secondary education (ninth grade) given the conclusion of primary education (eighth grade) is still around 80 per cent in 2008. The less successful education performance is observed in the case of $\mathrm{e}_{11}$. It was stable and declined slightly during the period of analysis. The proportion of individuals that have concluded secondary education and successfully completed the first year of college is only around 30 per cent.

The impact of family per capita income on specific GPPs $\left(\mathrm{e}_{0}, \mathrm{e}_{4}, \mathrm{e}_{8}\right.$, and $\left.\mathrm{e}_{11}\right)$ is analysed by the plot of three ordered segments. Figure 5 shows a strong convergence of the higher two-thirds of family per capita income on $\mathrm{e}_{0}$ and also a relative convergence of the bottom third. Figure 6 shows a relative narrowing of the gap among the three per capita income segments for $\mathrm{e}_{4}$, but convergence is not completely achieved. Both in the case of $\mathrm{e}_{0}$ and $\mathrm{e}_{4}$ the middle income segment affects the grade progression in a way that is more similar to the top income segment than the bottom one.

Figure 7 shows little convergence among the three per capita income segments, as GPP from primary to the first year of secondary (e8) increases over time. This improvement does not occur with a decline in income segmentation. The same lack of convergence is found in the GPP from secondary to the first year of tertiary education (college), e11, as depicted in Figure 8. This lack of 
convergence is aggravated by the fact that there is no growing trend of GPP in this segment. It is important to notice that in the case of these higher-grade transitions, the segment of middle-income families resembles more closely the bottom rather than the top income segment.

The analysis of Figures 7 and 8 confirms the finding for average schooling in Figures 2 and 3, namely, that despite some convergence in $\mathrm{e}_{0}$ and $\mathrm{e}_{4}$, social stratification at higher grade transitions is strong enough to keep differentials by categories within average schooling. As will be shown below, average schooling is just the final integration of all school transitions.

\section{Figure 4:}

School progression probability: $1^{\text {st }}$ grade of Elementary school $(\mathrm{e} 0), 5^{\text {th }}$ grade of Elementary school, 1st grade of High school (e8) and college (e11) in Brazil, 19812008

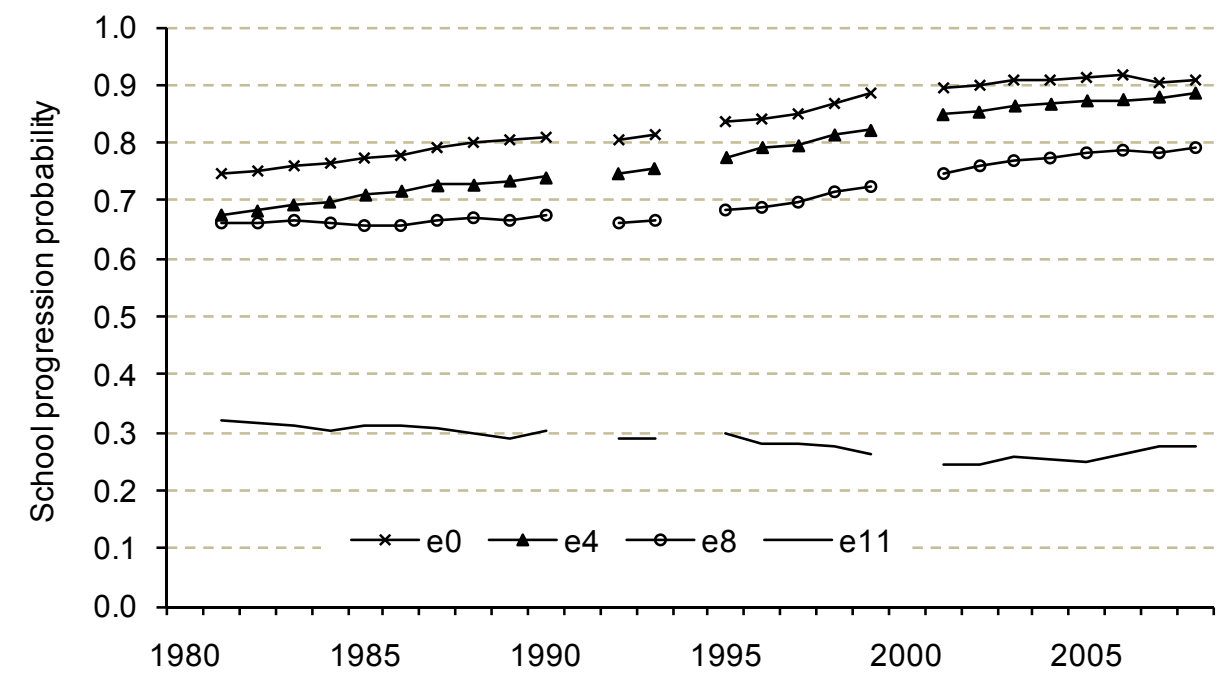

Source: PNAD 1981 and 2008 
Figure 5:

School progression probabilities to the $1^{\text {st }}$ grade of Elementary school by selected quantiles of real family income per head in Brazil, 1981-2008

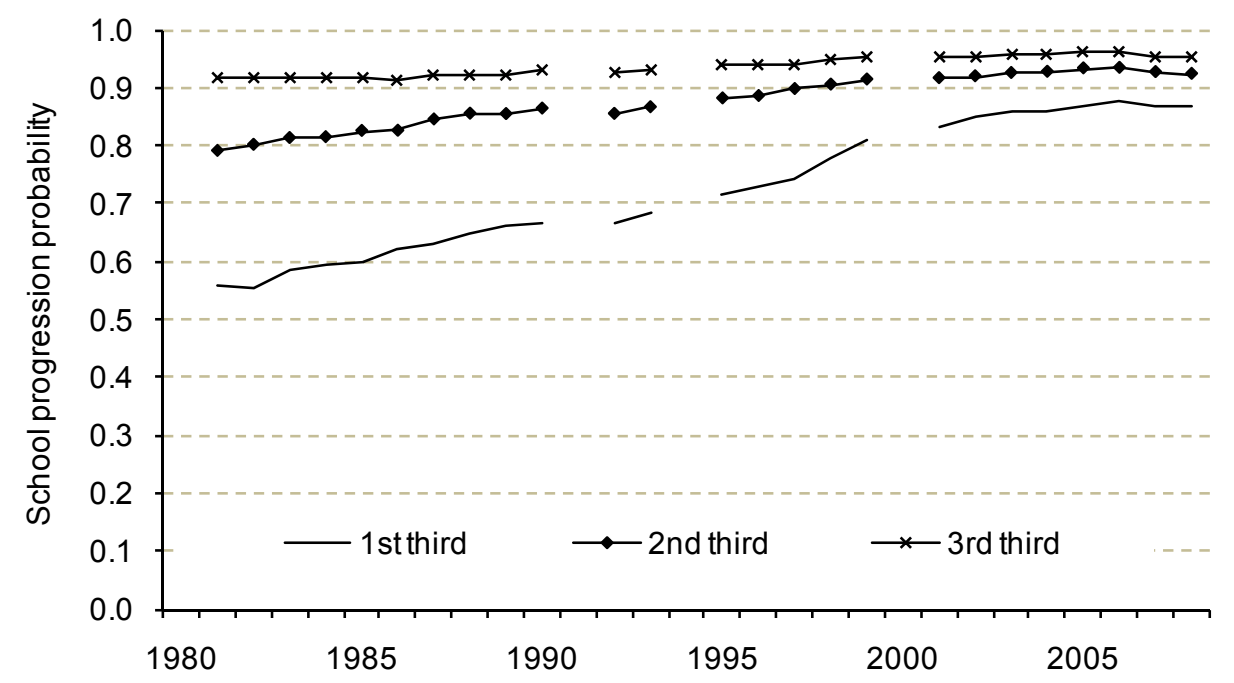

Source: PNAD 1981 and 2008

\section{Figure 6:}

School progression probabilities to the $5^{\text {th }}$ grade of Elementary school by quantile of real family income per head in Brazil, 1981-2008

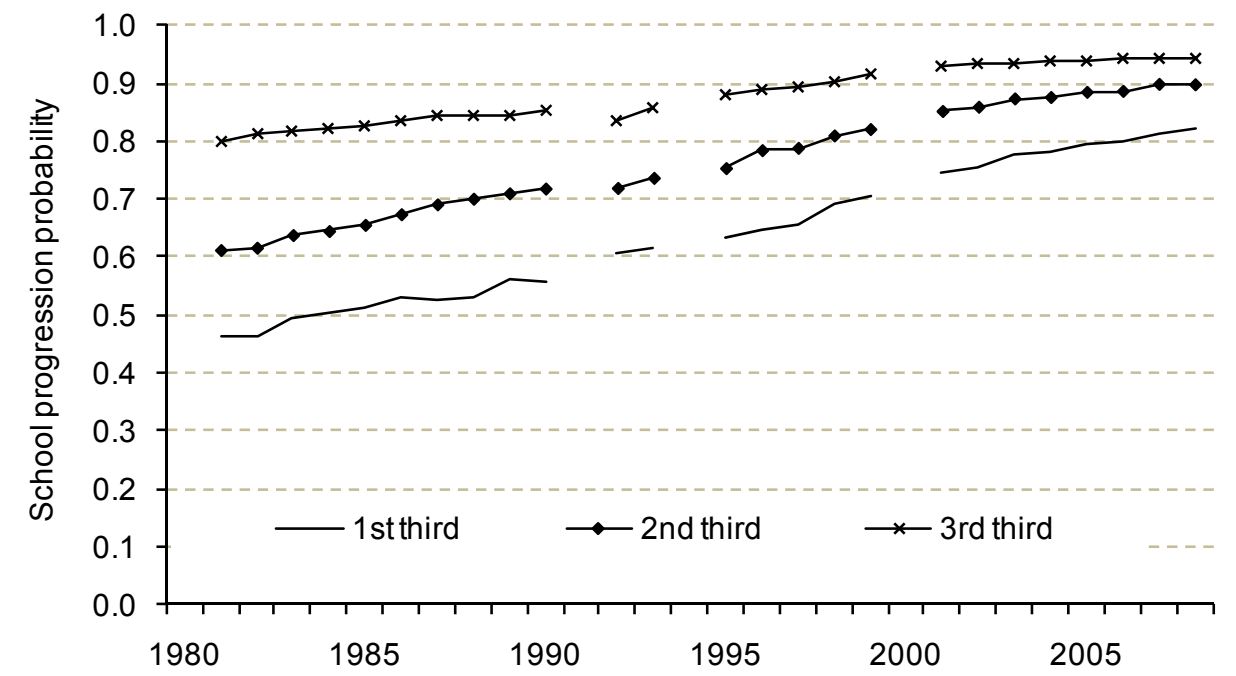

Source: PNAD 1981 and 2008 
Figure 7:

School progression probabilities to the $1^{\text {st }}$ grade of High school by quantile of real family income per head in Brazil, 1981-2008

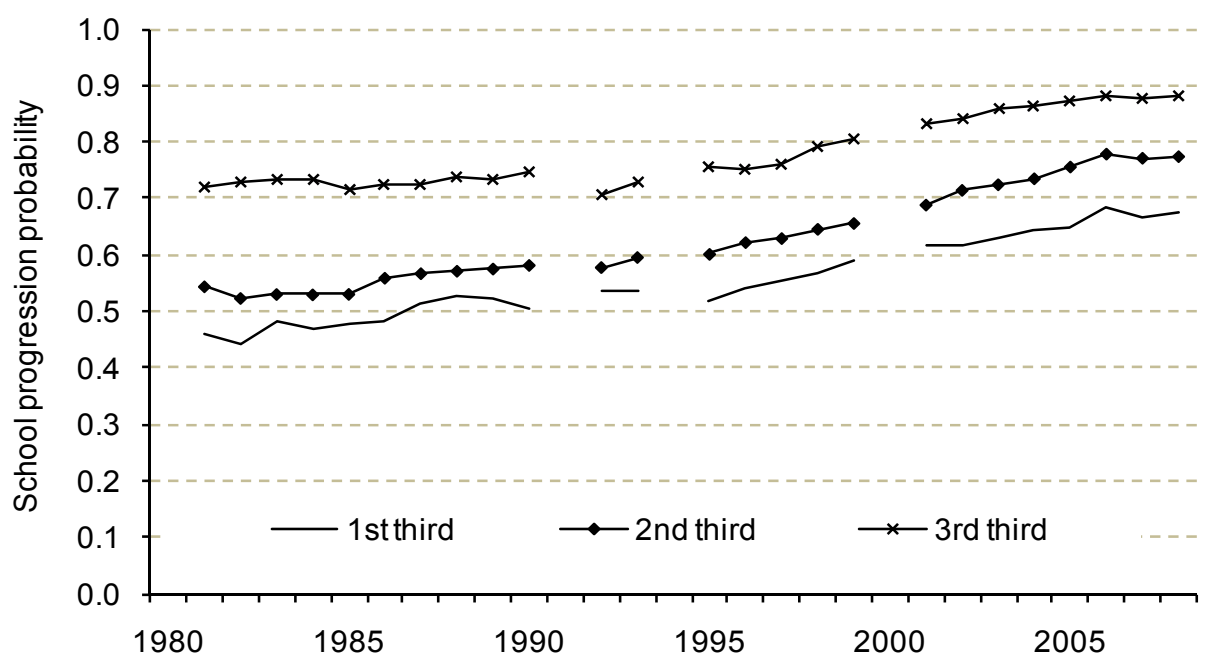

Source: PNAD 1981 and 2008

\section{Figure 8:}

School progression probabilities to the $1^{\text {st }}$ grade of College by selected quantiles of real family income per head in Brazil, 1981-2008

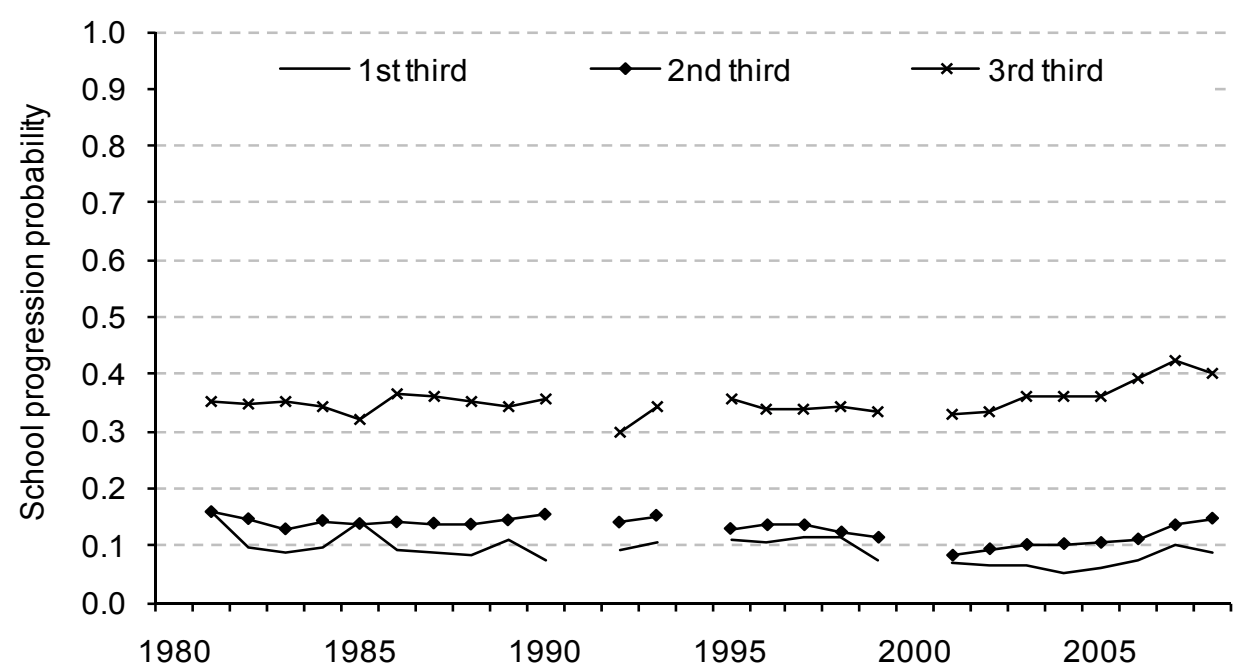

Source: PNAD 1981 and 2008 


\section{From GPP to average schooling and a decomposition exercise}

GPP(k) or $e_{\mathrm{k}}$ is the probability of completing grade $k+1$ given that you have completed grade $k$ previously. From Equation 1 it is possible to obtain the proportion of a cohort with at least $k$ years of study, $e_{0, k}$. By definition, $e_{0,0}=1$, meaning that the entire cohort has at least zero years of study completed.

$$
\begin{aligned}
& e_{0,1}=e_{0} \\
& e_{0,2}=e_{0} \cdot e_{1} \\
& \ldots \\
& e_{0 k}=e_{0} \cdot e_{1} \ldots e_{k-1}
\end{aligned}
$$

Finally, average schooling can be calculated by the application of the interacted expectations, which is the summation of the probabilities that education is greater or equal to all possible attainable values. If the maximum grade possible is 17, then $\mathrm{k}$ varies from 0 to 17 (Rios-Neto 2004) in accordance with Formula 5 below:

$$
e=\sum_{k} e_{0, k}=\sum_{k} \prod_{k} e_{k-1}
$$

It is possible to perform a decomposition exercise based on the formula above, in order to evaluate the role of each $\operatorname{GPP}(\mathrm{k})$ on the variation of average schooling between two cohorts or two periods (considering a synthetic cohort interpretation). The decomposition may be explained in three stages.

\section{First stage of decomposition}

- Step 1: Obtain the grade progression probabilities $\mathrm{e}_{\mathrm{k}}$ for two cohorts (or two periods - synthetic cohort approach). Denote $\mathrm{e}_{\mathrm{kj}}$ the grade progression probability $k$ for the $j$-th cohort, $j=1,2$.

- Step 2: Compute the proportion of the cohort with at least $k$ years of study $\mathrm{e}_{0, \mathrm{k}}$ for the two cohorts. Denote $\mathrm{e}_{0, \mathrm{kj}}$ the proportion in the $j$-th cohort, $j=1,2$, with at least $k$ years of schooling. 2.

- Step 3: Compute the average years of schooling for each cohort, $e_{j}, j=1$,

This first stage of the decomposition could be illustrated in Table 1. For an extensive description of the notations, please refer to the glossary in the appendix. 
Table 1:

Example of the implementation of the first stage of the decomposition

\begin{tabular}{|c|c|c|c|c|c|}
\hline \multicolumn{3}{|c|}{ Step 1: Obtaining $\mathrm{e}_{\mathrm{k}}$ for cohort 1 and 2} & \multicolumn{3}{|c|}{ Step 2: Computing $\mathrm{e}_{0, \mathrm{k}}$ for cohort 1 and 2} \\
\hline $\mathrm{e}_{\mathrm{kj}}$ & Cohort 1 & Cohort2 & $\mathrm{e}_{0, \mathrm{kj}}$ & $\mathrm{e}_{0, \mathrm{k} 1}$ & $\mathrm{e}_{0, \mathrm{k} 2}$ \\
\hline $\mathrm{e}_{0 \mathrm{j}}$ & $\mathrm{e}_{01}$ & $\mathrm{e}_{02}$ & $\mathrm{e}_{0,1 \mathrm{j}}$ & $\mathrm{e}_{01}$ & $\mathrm{e}_{02}$ \\
\hline $\mathrm{e}_{1 \mathrm{j}}$ & $\mathrm{e}_{11}$ & $\mathrm{e}_{12}$ & $\mathrm{e}_{0,2 \mathrm{j}}$ & $e_{11} \cdot e_{0,11}$ & $\mathrm{e}_{12} \cdot \mathrm{e}_{0,12}$ \\
\hline$\cdots$ & $\cdots$ & $\cdots$ & $\cdots$ & $\cdots$ & $\cdots$ \\
\hline $\mathrm{e}_{(\mathrm{k}-1) \mathrm{j}}$ & $\mathrm{e}_{(\mathrm{k}-1) 1}$ & $\mathrm{e}_{(\mathrm{k}-1) 2}$ & $\mathrm{e}_{0,(\mathrm{k}-1) \mathrm{j}}$ & $\mathrm{e}_{(\mathrm{k}-1) 1} \cdot \mathrm{e}_{0,(\mathrm{k}-2) 1}$ & $\mathrm{e}_{(\mathrm{k}-1) 2} \cdot \mathrm{e}_{0,(\mathrm{k}-2) 2}$ \\
\hline$e_{k j}$ & $\mathrm{e}_{\mathrm{k} 1}$ & $\mathrm{e}_{\mathrm{k} 2}$ & $\mathrm{e}_{0, \mathrm{kj}}$ & $\mathrm{e}_{\mathrm{k} 1} \cdot \mathrm{e}_{0,(\mathrm{k}-1) 1}$ & $\mathrm{e}_{\mathrm{k} 2} \cdot \mathrm{e}_{0,(\mathrm{k}-1) 2}$ \\
\hline \multicolumn{3}{|c|}{ Step 3: Computing e for cohort $t$ and $t 1$} & $\mathrm{e}_{\mathrm{j}}$ & $Z_{k} e_{0, k j}$ & $e_{0, k j}$ \\
\hline
\end{tabular}

\section{Second stage of decomposition}

In the second stage of the decomposition, we have to simulate the counterfactual years of schooling of the oldest cohort equivalent to a marginal change in the proportion in the cohort with $k$ years of schooling obtained from the younger cohort. Therefore, in this stage, we have two steps:

- Step 1: Replace recursively, one-by-one, the proportion of the oldest cohort with at least $k$ years of schooling (in our example, $\mathrm{e}_{0, \mathrm{k} 1}$ ) with the same proportion for the younger cohort (in our example, $\mathrm{e}_{0, \mathrm{k} 2}$ ). Using this procedure we will estimate the counterfactual average schooling that would exist if the proportion of the oldest cohort with at least $k$ years of schooling were the same as that of the youngest cohort. Note that, in the k-th simulation, you should only have the grade progression probabilities for the youngest cohort. It is important to highlight that this procedure may be implemented with the grade progression probabilities $\mathrm{e}_{\mathrm{k}}$, as a formal relationship has been demonstrated between them and the proportion of the cohort with at least $k$ years of schooling

- Step 2: Compute the counterfactual average schooling for each simulation.

We present an example of how to perform this second stage in Table 2. In this case, in order to simplify the demonstration, we present the decomposition implemented by means of the recursive substitution of the grade progression probabilities $\mathrm{e}_{\mathrm{k}}$. 
Table 2:

Example of the implementation of the second stage of the decomposition: obtaining the counterfactual average years of schooling with grade progression probabilities

\begin{tabular}{|c|c|c|c|c|c|c|}
\hline \multirow{2}{*}{$\mathrm{e}_{\mathrm{k} 1}$} & \multirow{2}{*}{$\mathrm{e}_{\mathrm{k} 2}$} & \multicolumn{5}{|c|}{ Simulation } \\
\hline & & $\mathrm{e}_{0, \mathrm{k} 1}(\operatorname{step} 1)$ & $\mathrm{e}_{0, \mathrm{k} 1}(\mathrm{step} 2)$ & $\ldots$ & $\mathrm{e}_{0, \mathrm{k} 1}(\operatorname{step}(\mathrm{k}-1))$ & $\mathrm{e}_{0, \mathrm{k} 1}(\operatorname{step}(\mathrm{k}))$ \\
\hline $\mathrm{e}_{01}$ & $\mathrm{e}_{02}$ & $\mathrm{e}_{02}$ & $\mathrm{e}_{02}$ & $\ldots$ & $\mathrm{e}_{02}$ & $\mathrm{e}_{02}$ \\
\hline $\mathrm{e}_{11}$ & $\mathrm{e}_{12}$ & $\mathrm{e}_{02} \cdot \mathrm{e}_{11}$ & $\mathrm{e}_{02} \cdot \mathrm{e}_{12}$ & $\cdots$ & $e_{02} \cdot e_{12}$ & $\mathrm{e}_{02} \cdot \mathrm{e}_{12}$ \\
\hline$\ldots$ & $\cdots$ & $\cdots$ & $\cdots$ & $\cdots$ & $\cdots$ & $\cdots$ \\
\hline $\mathrm{e}_{(\mathrm{k}-1) 1}$ & $\mathrm{e}_{(\mathrm{k}-1) 2}$ & 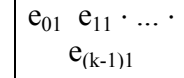 & $\mathrm{e}_{01} \cdot \mathrm{e}_{11} \cdot \ldots \cdot \mathrm{e}_{(\mathrm{k}-1) 1}$ & $\cdots$ & $\mathrm{e}_{02} \cdot \mathrm{e}_{12} \cdot \ldots \cdot \mathrm{e}_{(\mathrm{k}-1) 2}$ & $\mathrm{e}_{02} \cdot \mathrm{e}_{12} \cdot \ldots \cdot \mathrm{e}_{(\mathrm{k}-1) 2}$ \\
\hline $\mathrm{e}_{\mathrm{k} 1}$ & $\mathrm{e}_{\mathrm{k} 2}$ & $\begin{array}{r}\mathrm{e}_{01} \cdot \mathrm{e}_{11} \cdot \ldots \cdot \\
\mathrm{e}_{(\mathrm{k}-1) 1} \cdot \mathrm{e}_{\mathrm{k} 1}\end{array}$ & $\mathrm{e}_{01} \cdot \mathrm{e}_{11} \cdot \ldots \cdot \mathrm{e}_{(\mathrm{k}-1)} 1 \cdot \mathrm{e}_{\mathrm{k} 1}$ & $\cdots$ & $\mathrm{e}_{01} \cdot \mathrm{e}_{11} \cdot \ldots \cdot \mathrm{e}_{(\mathrm{k}-1) 1}$ & $\mathrm{e}_{02} \cdot \mathrm{e}_{12} \cdot \ldots \cdot \mathrm{e}_{(\mathrm{k}-1) 2}$ \\
\hline $\mathrm{e}(\operatorname{sim})$ & & $\begin{array}{c}\text { sum } \\
0, \mathrm{k} 1(\mathrm{step} 1) \\
\text { for all k }\end{array}$ & $\begin{array}{c}\text { sum } \\
\mathrm{e}_{0, \mathrm{k} 1}(\mathrm{step} 2) \\
\text { for all } \mathrm{k}\end{array}$ & $\ldots$ & $\begin{array}{c}\text { sum } \\
\mathrm{e}_{0, \mathrm{k} 1}(\operatorname{step}(\mathrm{k}-1)) \\
\text { for all } \mathrm{k}\end{array}$ & $\begin{array}{l}\text { sum } \\
\mathrm{e}_{0, \mathrm{k} 1}(\operatorname{step}(\mathrm{k})) \\
\text { for all } \mathrm{k}\end{array}$ \\
\hline
\end{tabular}

\section{Third stage of decomposition:}

Finally, we perform the decomposition exercise. The aim of this procedure is to obtain the relative gain in the average schooling between the two cohorts for the contributions of changes in each grade progression probability. The inputs for this decomposition are the simulated average years of schooling of the second stage. The procedure should be summarised in two steps:

- Step 1: Compute the difference between the simulated years of schooling at each transition and the average schooling for the oldest cohort.

- Step 2: Compute the relative gain in the average schooling between the two cohorts for the contributions of changes in each grade progression probability.

The final stage of the decomposition is presented in Table 3.

In Figure 9, we perform the decomposition of educational attainment between the synthetic cohorts of 1981 and 2008 in order to ascertain which grades were more important in explaining the variation in average years of schooling in Brazil during this period. 
Table 3:

Example of the implementation of the third stage of the decomposition: obtaining the contribution of each GPP to the changes in average years of schooling between two cohorts

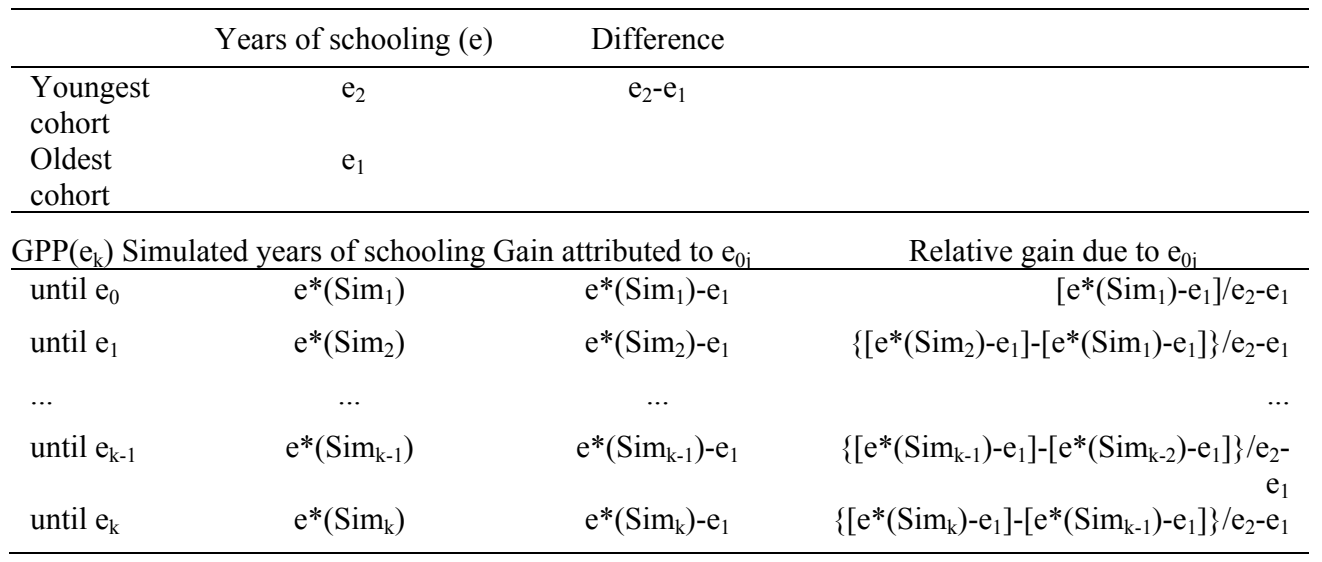

Figure 9:

The role of GPP(i) or e(k) to the change in average schooling in Brazil, 1981-2008

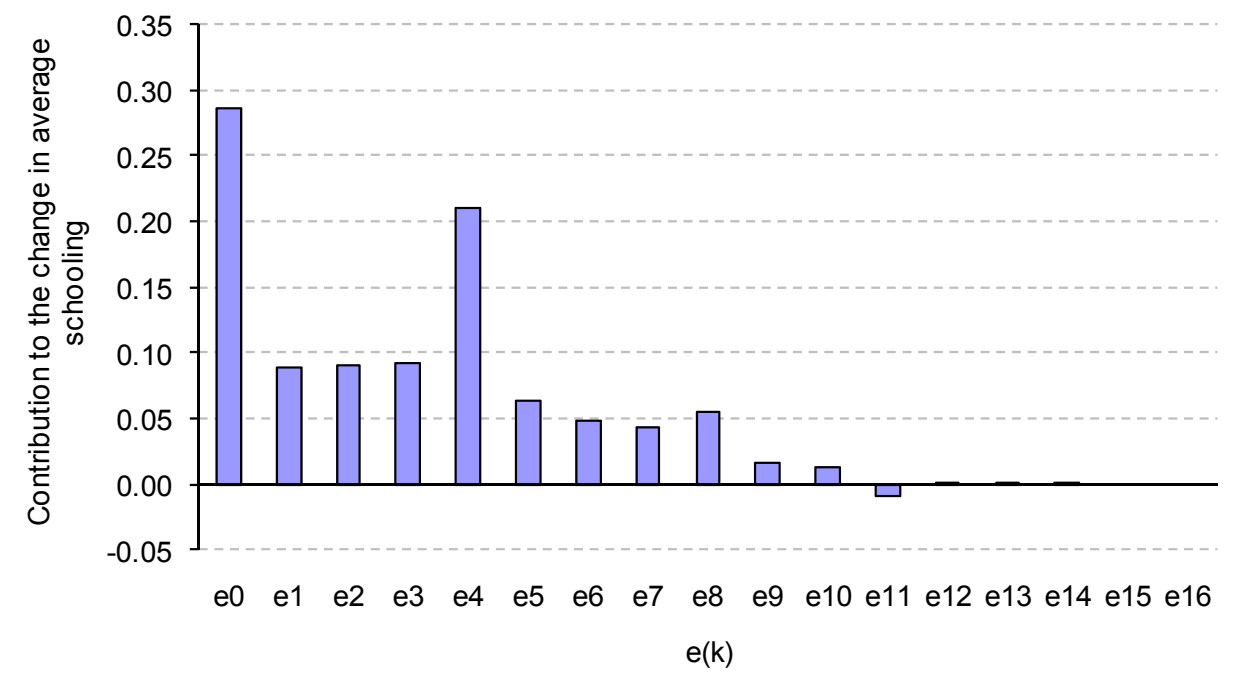

Source: PNAD 1981 and 2008

The decomposition presented in Figure 9 shows that the grade progression at the first grade, $\left(\mathrm{e}_{0}\right)$, accounted for nearly 30 per cent of the change in years of schooling between 1981 and 2008. The second most important grade progression explaining the change in years of schooling was the grade progression at fifth grade $\left(\mathrm{e}_{4}\right)$, which accounted for more than 20 per cent of the change. These two 
transitions together accounted for nearly half of the average schooling change in the period.

In the second decomposition exercise we consider three sub-periods in order to describe changes in the role of GPPs to justify the changes in educational attainment: 1981-1989, 1990-1999 and 2001-2008. The results are presented in Figure 10. The successful completion of first grade was the most important progression explaining the gains in average schooling between 1981 and 1989, accounting for more than 60 per cent of the change. The period between 1990 and 1999 presents a similar pattern, but the relative weight of $\left(\mathrm{e}_{4}\right)$ increases. The role of $\left(\mathrm{e}_{0}\right)$ definitively declines in the period between 2001 and 2008, when $\left(\mathrm{e}_{4}\right)$ becomes the most important transition explaining the gains in average schooling. During this last period, several transitions of grades in primary education become equally important for explaining changes in educational attainment.

Figure 10:

The role of GPP(i) or $\mathrm{e}(\mathrm{k})$ to the change in average schooling by three sub- periods in Brazil

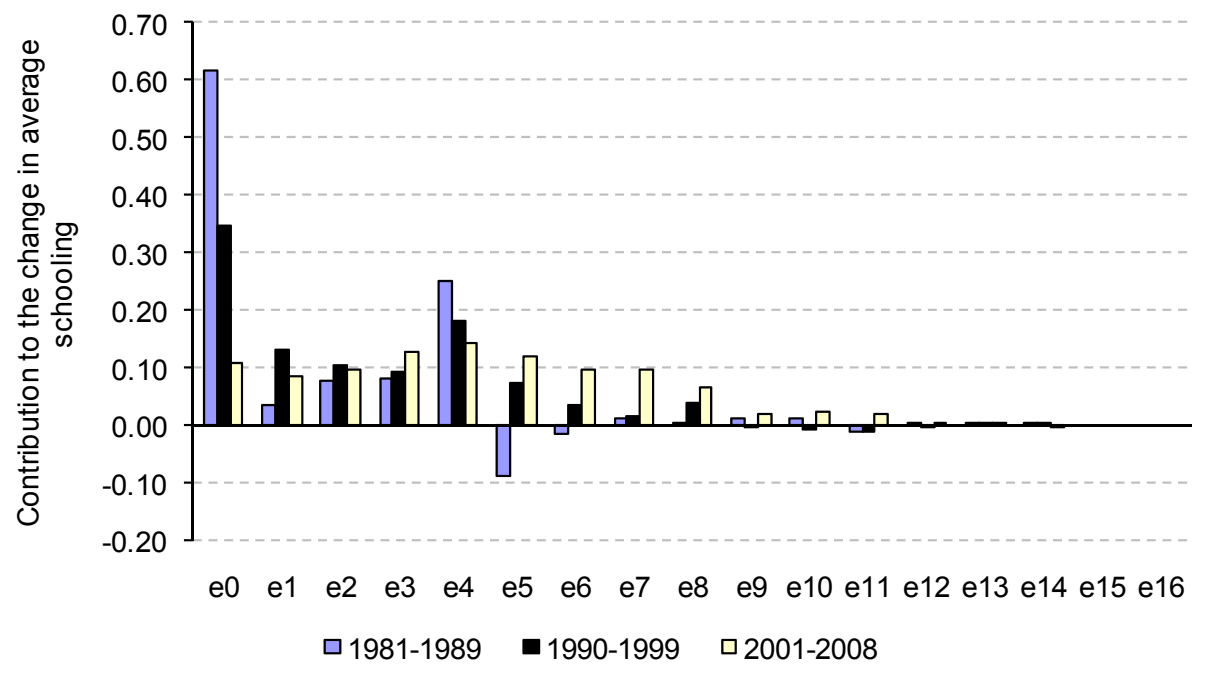

Source: PNAD 1981 and 2008

\section{School transition models and educational stratification in Brazil}

The first studies aiming to evaluate the effect of social origins on educational results were published in the 1960s. The standard tool for these studies was the application of linear regression models and the choice of completed years of 
schooling as the dependent variable. Early evidence indicated stability in educational stratification by a constant effect of social origins between cohorts (Blau and Duncan 1967; Duncan, Featherman and Duncan 1972; Hauser and Featherman 1976; Sewell and Hauser 1975). Boudon (1974) was the first to consider education as the result of a series of grade progressions. The analytical framework used by him was the linear probability model, showing a declining inequality of educational opportunities among the cohorts.

Mare $(1979,1980,1981)$ criticised the empirical literature on educational stratification. He suggested that two key issues should be accounted for when analysing changes in the educational inequality of opportunity: 1. the dispersion of formal education in a population, 2. given a certain dispersion level of schooling, the extent to which different population groups are allocated according to educational outcome. The latter question deals with the association between social origins and educational outcome. Previous studies that used the highest schooling as a dependent variable were mistaken for they should have considered the difference between changes in inequality of educational opportunities and expansion of education. Educational expansion could compensate for the social selection process in acquiring education.

Mare $(1979,1980)$ also pioneered an important selectivity hypothesis, stating that the role of social origins would decline as the grade progression moved from lower to higher grades. This decline was due to the operation of a selectivity mechanism in which the progression (survival) to higher grades among families with lower socioeconomic status (SES) would take place among the brightest students living in these families (an unobserved trait), a fact which would lead to a decline in the impact of socioeconomic status variables (SES) on these higher grade progressions. This hypothesis has been tested in several international contexts (Mare 1993; Shavit and Blossfeld 1993; Cameron and Heckman 1998; Lucas, 2001; Vallet 2007). The formulation is clear, if the coefficient of the SES variables in a period grade progression regression declines as the progression variable is associated with higher grades, then there is a selectivity process.

The selectivity hypothesis mentioned above should be tested in a period context, in a given year. Another hypothesis advanced by Mare $(1979,1980)$ is associated with the time frame during which a school system expansion takes place. In this case, for a specific grade, the impact of SES variables decline through time. Mare suggests that as the strength of SES declines in certain grades through time with the expansion of the school system, at the same time there is a migration of difficulties and selectivity to higher grades, so that there is an increasing impact of SES on higher grades. This process occurs because the differential attrition rates throughout the school career reduce the heterogeneity between children from different social classes, with respect to unobservable determinants of progression and school continuation decisions-ability and motivation. This therefore reduces the observed effect of social origins but at the 
same time the expansion of education brings back this heterogeneity at higher grades, thus increasing the impact of SES.

In other words, an analysis of different birth cohorts during a period of expansion in the education system will increase the proportion of students exposed to the probability of making certain transitions throughout their years of schooling. This greater number of survivors at each transition would raise the population composition in terms of unobserved heterogeneity. Consequently, the effects of family background variables on the grade progression chances would rise among the most recent cohorts. Selectivity is thus displaced along the school trajectory.

Beginning with the evidence from Mare, an intense debate in the literature on educational stratification had started concerning: the adequacy of the logistic school transitions model; the behaviour of the coefficients over the school grades, or the validity of a selective process in school career; and finally the effect of an educational expansion to the level of inequality of educational opportunities. In particular, the study organised by Shavit and Blossfeld (1993) brought together the results for 13 countries on the development of educational stratification. In 11 of these, Mare's prediction was confirmed, i.e. the estimated effect of family background decreased starting from the bottom to the top school transitions.

It is possible to summarise at least six interpretations for the behaviour of the educational stratification, according to Shavit and Blossfeld (1993). The first one is the modernisation hypothesis, which states that increasing modernisation and educational expansion will always result in a decrease along the educational career and time. The second is named reproduction hypothesis and argues that the effect of the social origins declines in the first transitions but not in later ones, as a result of the upper strata maintaining the privilege of access to higher education. On the other hand, the third hypothesis strengthens the concept that social-origin effects will decline at some transitions if and only if the attendance rates in these transitions of the upper classes are universal. This hypothesis is called maximally maintained inequality. The fourth hypothesis, socialistic transformation, stated that the socialist regime brought an initial decrease in the inequality of educational opportunities, but that later there was a reversal. The life-course hypothesis focuses on the life cycle dependency of the students. The hypothesis argues that the effects of the decline of social origins across educational transitions, as well as the expansion of primary and secondary education, cause a reduction of the inequality of educational opportunities across cohorts. Finally, the differential selection hypothesis comprehends Mare's contribution to this literature, predicting that the effects of social origins decline across cohorts as education is expanded, but that these effects increase between cohorts in later stages of the educational trajectory.

In order to evaluate the changes in educational stratification in four Latin American countries (Brazil, Chile, Colombia, and Mexico), Torche (2010) employed an ordered regression model which estimates two quantities of interest: 
the unconditional probability of reaching a particular educational level and the conditional probability of the transition from one level to the next. The author shows that the findings from the study are rather similar across countries and suggest equalisation in early educational transitions, as a result of the upper class saturation. However, her findings concerning the later transitions imply an increase in inequality of opportunities, except for Chile. According to the author, this could be explained by a declining demand of the poor for higher education in the context of an economic crisis, and partly by the inability of the system to expand the supply of enrolment slots in later stages.

Buis (2005) has recently developed some advances in the school transitions framework. He suggested that the selection process taking place in the educational trajectory has to be analysed taking into consideration the location and enforcement of the cut-off value. According to the author, these aspects of the selection process have a substantive interpretation: a decrease in the enforcement of the cut-off value reduces inequality since the measure for the social origins becomes irrelevant for selecting students. He has also shown that these components of the selection process should be measured in the usual discrete time logistic model, with the inclusion of extra parameters in the model: for instance, dividing the respondents into different cohorts and, with the use of dummy variables, performing the estimation of the cut-off values and their enforcement for each individual cohort. Another strategy would be to include a linear trend in the enforcement of the cut-off value. He applied this new approach to data relating to the Netherlands for birth cohorts from 1880-1975, and found that the trends in the location and the enforcement of the cut-off point were similar.

Another contribution of Buis (2010) was the demonstration of a formal relationship between inequality of educational opportunities (IEOpp) and inequality of educational results (IEOut). Within his framework, it is possible to decompose effects of changes in the distribution of education on IEOut. The author applied this methodological relationship to data from the Netherlands, for children aged 12 between 1905 and 1991. An important finding of his exercise was the decrease in the importance of the first transition and the increase in the importance of the second transition to temporal changes in IEOut. This result somehow corroborates our GPP decomposition for Brazil, as it was shown in previous sections.

Regarding Mare's first hypothesis, previous empirical studies conducted in Brazil are often controversial, although some proxies for social origins corroborate his statement. Silva and Souza (1986) pioneered the model of school transition, concluding that the coefficients of variables that measure the social origins have declined over the school trajectory. Fernandes (2001) showed that most measures of social origin had a decreasing pattern from the lowest to the highest academic transition, except in the cases of gender and race. In the same direction, Silva and Hasenbalg (2002) found that only the effect of the head of the household's education on the likelihood of grade progression showed the 
decreasing behaviour predicted by Mare. Rios-Neto et al. $(2002,2003)$ found, in their first article, that the family variables were stronger in grade progression for the first grade at primary school, which supports the Mare's first hypothesis. However, in their second article, using other variables, they found that impact of the social origins did not actually decrease.

Mare's second hypothesis is clearly corroborated by the Brazilian literature, if we analyse trends at primary-school level, which has been the level that benefited the most from the educational expansion policies. Silva (2003) showed that there was a reduction in the effects of social origins in the first transition, especially during the 1990s. Higher transitions, which were investigated, presented stable effects over time (education of the head of the household) or even increased (sex of the head of the household and region of residence). Finally, Ribeiro (2009) concluded there was a decline in the role of the mother's education and of the father's occupation on the odds of completing the first school transitions.

In summary, most Brazilian studies that investigated the relationship between social background and school progress in Brazil corroborated the hypothesis of a declining role of the social origins on the cohorts in the early school transitionsusually up to the fifth grade of primary school. In turn, the hypothesis of declining school transitions along the social origins is not endorsed in most studies.

In order to test the two hypotheses proposed by Mare in relation to the Brazilian case, we applied the micro data from the National Survey by Household Sampling (PNAD-IBGE). For each period of analysis, individuals were collected from households where they were classified as sons and daughters of the head of the household, aged between seven and 25 years (school-age individuals). For some individuals we controlled attributes in order to consider different educational outcomes: sex, race and residence in metropolitan or urban areas. Social background information was collected on the head of the household's schooling, sex, race/colour, number of siblings living in the same household and the individual's occupational status. The head of the household's variables ${ }^{3}$ were the basis for the test of the hypotheses discussed above. The variable occupational status of the head of the household includes the following options: High occupational status, Low occupational status, No occupation status of the head of the household, and the omitted dummy variable No occupation status. High occupational status included High and Medium status for Machado et al. (2004), while Low status included domestic and manual occupations in the authors' classification.

In order to calculate $\operatorname{GPP}(\mathrm{k})$, it is necessary to filter individuals given the minimum age to conclude grade $k$, and to filter individuals in the sample as to include everyone who completed at least grade $k$. In this sense, with increasing $k$

3 The selection of variables follow the tradition of multivariate analysis of educational attainment in Brazil conducted by authors such as Beltrão and Alves (2009), Henriques (2002), Neri et al. (2006), Silva and Hasenbalg (2002), Rios-Neto et al. (2002), Rios-Neto et al. (2003), Riani and Rios-Neto (2008). 
the minimum age increases and the number of people having completed at least grade $k$ declines. GPP can be applied to all birth cohorts since it is not based on current school attendance but on the idea that someone has concluded at least grade $k$ and has also concluded grade $k+1$. The timing during which this grade progression took place is not clearly defined.

All regressions applied to the different GPP were estimated by a logit regression model with binary response in accordance with the formalisation below:

$$
\ln \left(\frac{p i j}{1-p i j}\right)=\beta_{0 j}+\sum_{k} \beta_{j k} \cdot X_{i j k}+\sum_{m} \beta_{j m} \cdot X_{i j m},
$$

where $\mathrm{p}$ is GPP and $\mathrm{j}$ is the initial grade completed, $i$ indexes individuals, $k$ stands for family variables and $m$ indexes stand for the individual attributes. While testing the hypotheses associated with Mare (1980), the family background variables $\left(\mathrm{X}_{\mathrm{ijk}}\right)$ are the key factors to consider. To the extent that there is a latent attrition in grade promotion mediating the relationship between social origin and grade transition, there may be a change in the estimated coefficients of the family background variables as the grade increases $\left(\mathrm{X}_{\mathrm{ijk}}\right)$.

Three periods are considered for estimation: 1986, 1999 and 2008. Twelve estimations are performed for each year, in order to account for 12 grade transitions, $\mathrm{e}_{\mathrm{k}}$, defined as the transition to conclude grade $k+1$, given that the person had previously concluded grade $k$. Estimations go from grade promotion in grade $1\left(\mathrm{e}_{0}\right)$ until grade promotion in grade $12,\left(\mathrm{e}_{11}\right)$, which is the first year of college. In total, 36 regressions were estimated, combining 12 (grade transitions) with 3 (period estimations).

The results for the 12 logit regressions for GPPs in years 1986, 1999 and 2008 are presented in the appendix. The key variable for the analysis in this paper is the coefficient of the head of the household's education on the transitions. However, we consider only four crucial transitions to the analysis: progression probability to the first grade of primary school $\left(\mathrm{e}_{0}\right)$; progression probability to the fifth grade of primary school, given the conclusion of the fourth grade $\left(\mathrm{e}_{4}\right)$; progression probability to the first grade of secondary school, given the conclusion of the eighth grade of elementary school $\left(\mathrm{e}_{8}\right)$; and, finally, the progression probability to the first year of tertiary school, given the conclusion of the third grade of secondary education $\left(\mathrm{e}_{11}\right)$.

The presentation of the results in this manner is due to two reasons. First, these four transitions may be considered as crucial school continuation decisions, relating to the express transitions between levels of education (primary, secondary and tertiary) and, in the case of $\mathrm{e}_{0}$, the transition of no education to the school entry. Also, these transitions are consistent with the credentials approach or the so-called "diploma effect" (Ramos and Vieira, 1996). Second, as shown in the previous sections, these grades were the most significant ones in explaining the Brazilian gains in educational attainment. 
Figure 11 displays the estimated coefficients for the four selected school transitions concerning the effect of the head of the household's education on each grade progression. The analysis of Figure 11 provides the basis for the answer to the main theoretical hypothesis reviewed in this paper.

Mare's first hypothesis is not confirmed in the Brazilian case. In other words, the impact of the head of the household's education does not decline as we move in transitions from lower to higher grades in a given period. In fact, Figure 11 shows clearly that the Brazilian education system has undergone extreme changes in the grade progression probabilities, and that these changes have resulted in modifications in the level of inequality of educational opportunities across transitions.

Mare's second hypothesis is partially confirmed by the Brazilian data. When comparing 1986 to 2008, there is a clear decline in the impact of the head of the household's education on $\mathrm{e}_{0}$ and $\mathrm{e}_{4}$. Mare suggests that as the school system expands, there is a migration of selectivity to higher grades. Indeed, $\mathrm{e}_{8}$ increases between 1986 and 1999 but remains constant at this level in 2008. This result is compatible with the notion that the school expansion during the 1990s concentrated on the lower primary level, while the upper primary level still experienced some expansion difficulties. The problem continued to exist at the secondary and tertiary levels, and it was aggravated with the migration of selectivity, as the coefficient for $\mathrm{e}_{11}$ in 2008 clearly indicates.

The results for 1999 do not follow a clear pattern for testing Mare's second hypothesis, but the comparison between 1986 and 2008 is clearly supportive of the hypothesis, as the previous discussion has shown. It is possible that the year 1999 was less affected because it was the precise time when the education expansion in the first four grades was taking place.

Figure 11:

Coefficients estimated in the school transition model for the head's education and selected transition in Brazil, 1986, 1999 and 2008

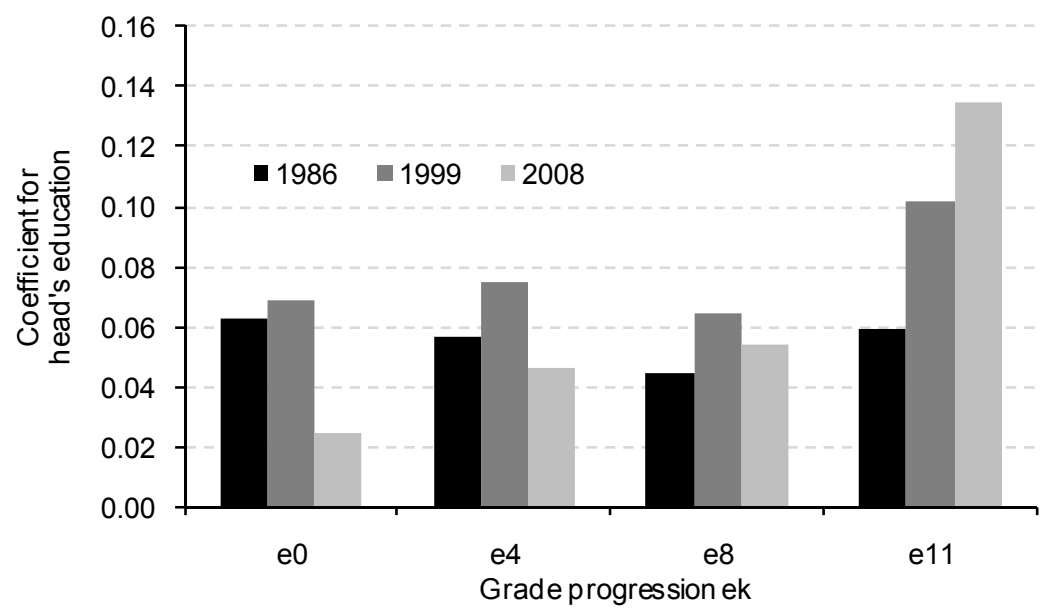




\section{Concluding remarks}

This paper tried to convey the relevance of grade progression probabilities to the study of education attainment and its determinants. To the extent that grade progression can be studied in a cohort or a period perspective, and that GPP resembles the demographic concept of parity progression ratio, this application may be labelled the demography of education.

A demography of education is well suited to the elaboration of decomposition exercises. The decomposition performed has indicated the crucial historical role of some key transitions in the increase of average schooling, particularly $\mathrm{e}_{0}$ and $\mathrm{e}_{4}$. The crucial role of $\mathrm{e}_{0}$ is replaced by $\mathrm{e}_{4}$ as the decomposition is performed in more recent periods, consistent with the behaviour found by Buis (2010) in the Netherlands. In a historical perspective, the key transitions $\left(\mathrm{e}_{0}, \mathrm{e}_{4}, \mathrm{e}_{8}\right)$ increased through time, with the exception of $\mathrm{e}_{11}$ that presented a flat profile.

The descriptive analysis has indicated a relative convergence of grade progression probability by socioeconomic variables, at least in the case of lower grades. In the higher grades, an increase in GPP took place in a parallel growth by socioeconomic segments and this stratification was strong enough to be preserved by the analysis of average schooling. Mare's first hypothesis was not confirmed, since the head of a household's education was an important determinant of GPP in key grades. Mare's second hypothesis was confirmed. There was a decline in the role of socioeconomic background at lower grades as the education system expanded through time. This decline was compensated by a migration of selectivity to higher grades.

\section{References}

Beltrão, K. I. and J. E. D. Alves. 2009. “A reversão do hiato de gênero na educação brasileira no século XX." Cadernos de Pesquisa 39 no.136.

Blau, P. M. and O. D. Duncan. 1967. The American Occupational Structure. London, The Free Press.

Blossfeld, H.-P. and Y. Shavit. 1993. "Persistent inequality: Changes in educational opportunities in thirteen countries." In: Persistent Inequality: Changes in Educational Opportunities in Thirteen Countries Boulder, Co: Westview Press.

Boudon, R. 1974. Education, opportunity and social inequality. New York: Wiley.Buis, M. 2005. "Two types of stringency of selection in education." Unpublished manuscript Available at «http://www.maartenbuis.nl/wp/cutoff_enforce.pdf».

Buis, M. L. 2010. "Not all transitions are equal: The relationship between inequality of educational opportunities and inequality of educational outcomes." In: M. Buis, Inequality of Educational outcome and inequality of educational opportunity in the Netherlands during the 20th century. PhD thesis, Chapter 6. Available at «http://www.maartenbuis.nl/dissertation/chap_6.pdf». 
Cameron, S. V. and J. J. Heckman. 1998. "Life cycle schooling and dynamic selection bias: Models and evidence for five cohorts of american males." The Journal of Political Economy 106(2): 262-333.

Duncan, O. D., D. L. Featherman, and B. Duncan. 1972. Socioeconomic Background and Achievement. New York, Seminar Press.

Hauser, R. M. and D. L. Featherman. 1976. "Equality of schooling: trends and prospects." Sociology of Education 49: 99-120.

Henriques, R. 2002. Raça e gênero no sistema de ensino: os limites das políticas universalistas na educação. Brasília: UNESCO.

Jenks, C. and L. Tach. 2006. "Would equal opportunity mean more mobility?" In: S. L Morgan, D. B. Grusky, and G. S. Fields (eds.). Mobility and Inequality. Stanford, California, Stanford University Press.

Lucas, S. R. 2001. "Effectively maintained inequality: education transitions, track mobility, and social background." The American Journal of Sociology 106(6): 1642-1690.

Machado, A. F., A. M .H. C. de Oliveira, and N. F. Carvalho. 2004. "Tipologia de qualificação da força de trabalho: uma proposta com base na noção de incompatibilidade entre ocupação e escolaridade." Nova Economia 14(2): 11-33.

Mare, R. 1979. "Social background composition and educational growth." Demography 16(1): 55-71.

Mare, R. 1980. "Social background and school continuation decisions." Journal of the American Statistical Association 75(370): 295-305.

Mare, R. 1981. "Change and stability in educational stratification." American Sociological Review 46(1): 72-87.

Mare, R. 1993. "Educational stratification on observed and unobserved components of family background." In: Y. Shavit and H.-P. Blossfeld (eds.) Persistent Inequality: Changing Educational Attainment in Thirteen Countries. Boulder, CO: Westview Press, chapter 15, pp. 351-376.

Marteleto, L. 2005. Family size, demographic change and educational attainment: the case of Brazil. Population Studies Center Research Report 05-584.

Neri, M., R. Moura, and P. Correa 2006. Infraestrutura e avanços educacionais. São Paulo, Fundação Getúlio Vargas, Centro de Políticas Sociais. Available at: «http://www4.fgv.br/cps/simulador/site_cps_educacao/WB_relatoriofinal.pdf».

PNAD 2008. Brazilian household sample survey (Pesquisa Nacional por Amostra de Domicílios). Microdata from 1986 to 2008, Brazilian Census Bureau, Rio de Janeiro: IBGE, 2009.

Pressat, R. 1972. Demographic analysis: methods, results, applications. Chicago, AldineAtherton.

Preston, S. H., P. Heuveline, and M. Guillot. 2001. Demography - Measuring and modeling population processes. Blackwell Publishers.

Ramos, L and M. L. Vieira. 1996. "A relação entre educação e salários no Brasil.” In: Economia Brasileira em Perspectiva. Rio de Janeiro: IPEA, 2nd ed.

Riani, J. de L. R. and E. L. G. Rios-Neto. 2008. "Background familiar versus perfil escolar do município: qual possui maior impacto no resultado educacional dos alunos brasileiros?" Revista Brasileira de Estudos Populacionais 25(2): 251-269.

Rios-Neto, E. L. G. 2004. "O método de probabilidade de progressão por série.” Chapter 1 In: E. L. G. Rios-Neto, J. de L. R Riani. (eds.) Introdução à Demografia da Educação. Campinas: Associação Brasileira de Estudos Populacionais. 
Rios-Neto, E. L. G. 2005. "Questões emergentes na análise demográfica: o caso brasileiro.” Revista Brasileira de Estudos Populacionais 22(2): 71-408.

Rios-Neto, E. L. G., C. C. César, and J. de L. R. Riani. 2002. "Estratificação educacional e progressão escolar por série no Brasil.” Pesquisa e Planejamento Econômic 32(3): 243-272.

Rios-Neto, E. L. G., J. de L. R. Riani, and C. C. César. 2003. Mother's or teacher's education? Educational stratification and grade progression in Brazil. Belo Horizonte, Maio.

Sewell, W. H. and R. M. Hauser. 1975. Education, occupation and earnings: achievement in the early career. New York, Academic press.

Shavit, Y. and H.-P. Blossfeld. 1993. Persistent Inequality: Changing Educational Attainment in Thirteen Countries. Boulder, Co: Westview Press.

Shavit, Y., M. Yaish, and E. Bar-Haim. 2007. "The persistence of persistent inequality." In: S. Scherer, R. Pollak, G. Otte, and M. Gangl. (eds.) From origin to destination. Trends and mechanisms in social stratification research. Frankfurt, New York: Campus, pp. 37-57.

Silva, N. do V. and C. Hasenbalg. 2002. "Recursos familiares e transições educacionais." Cad. Saúde Pública, Suplemento 18: 67-76.

Silva, N. do V., and A. de Mello e Souza 1986. "Um modelo para a análise da estratificação educacional no Brasil." Cadernos de Pesquisa 58: 40-52.

Torche, F. 2010. "Economic crisis and inequality of educational opportunity in Latin America." Sociology of Education 83: 85-110.

Vallet, L. A. 2007. "What can we do to improve the education of children from disadvantaged backgrounds?” In: M. S. Sorondo, E. Malinvaud, and P. Léna (eds.) Globalization and education: proceedings of the joint working group. The Pontifical Academy of Sciences, pp. 127-155. 


\section{Appendix}

Part I:

Glossary for the GPP decomposition

\begin{tabular}{l|c|c}
\hline Indicator & Description & Formula \\
\hline$P_{k+1}$ & $\begin{array}{c}\text { Number of people in the cohort that } \\
\text { concluded grade } k+1\end{array}$ & $e_{k j}=\frac{P_{(k+1) j}}{P_{k j}}$ \\
\hline$P_{k}$ & $\begin{array}{c}\text { Number of people in the cohort that } \\
\text { concluded grade } k\end{array}$ & \\
\hline $\mathrm{e}_{\mathrm{kj}}, k=0, \ldots, k$ & $\begin{array}{c}\text { Grade progression probability at grade } \\
k \text { for cohort } j\end{array}$ & $e_{j}=\sum_{k} e_{0, k j}$ \\
\hline $\mathrm{e}_{0, \mathrm{kj}}, k=0, \ldots, k$ & $\begin{array}{c}\text { Proportion in the cohort with at least } \\
k \text { years of schooling for cohort } j\end{array}$ & $e_{0 j} \cdot e_{1 j} \cdot \ldots \cdot e_{(k-1) j}$ \\
\hline$e_{j}$ & Years of schooling of cohort $j$ & $e^{2}$
\end{tabular}


Part II: Estimated school transitions model, Brazil.

Table A.1:

Results for the school transition model: 1986

\begin{tabular}{|c|c|c|c|c|c|c|c|c|c|c|c|c|}
\hline & $\mathrm{e} 0$ & e1 & e2 & e3 & e4 & $\mathrm{e} 5$ & e6 & e7 & e8 & e9 & e10 & e11 \\
\hline \multirow[t]{2}{*}{ Student is male } & -0.169 & -0.076 & -0.070 & -0.009 & -0.039 & -0.153 & -0.087 & -0.188 & -0.196 & 0.040 & -0.151 & -0.117 \\
\hline & {$[0.018]^{* *}$} & {$[0.024]^{* *}$} & {$[0.026]^{* *}$} & {$[0.027]$} & {$[0.026]$} & {$[0.032]^{* *}$} & {$[0.038]^{*}$} & {$[0.042]^{* *}$} & {$[0.043]^{* *}$} & {$[0.057]$} & {$[0.063]^{*}$} & [0.070] \\
\hline Student is white & 0.534 & 0.356 & 0.359 & 0.381 & 0.340 & 0.315 & 0.334 & 0.356 & 0.276 & 0.201 & 0.211 & 0.574 \\
\hline \multirow[t]{2}{*}{ Metropolitan } & 0.206 & 0.123 & 0.084 & 0.161 & 0.277 & 0.168 & 0.128 & 0.089 & -0.031 & -0.029 & 0.087 & -0.084 \\
\hline & {$[0.023]^{* *}$} & {$[0.029]^{* *}$} & {$[0.030]^{* *}$} & {$[0.031]^{* *}$} & {$[0.029]^{* *}$} & {$[0.035]^{* *}$} & {$[0.040]^{* *}$} & {$[0.044]^{*}$} & {$[0.045]$} & {$[0.060]$} & {$[0.065]$} & [0.072] \\
\hline \multirow[t]{2}{*}{ Head's education } & 0.063 & 0.034 & 0.035 & 0.046 & 0.057 & 0.042 & 0.026 & 0.029 & 0.045 & 0.037 & 0.021 & 0.059 \\
\hline & {$[0.003]^{* *}$} & {$[0.004]^{* *}$} & {$[0.004]^{* *}$} & {$[0.004]^{* *}$} & {$[0.004]^{* *}$} & {$[0.005]^{* *}$} & {$[0.005]^{* *}$} & {$[0.006]^{* *}$} & {$[0.006]^{* *}$} & {$[0.008]^{* *}$} & {$[0.009]^{*}$} & {$[0.009]^{* *}$} \\
\hline \multirow[t]{2}{*}{ Head is male } & 0.058 & 0.025 & 0.047 & 0.033 & -0.018 & -0.015 & -0.082 & 0.122 & -0.067 & 0.066 & 0.021 & -0.086 \\
\hline & {$[0.026]^{*}$} & {$[0.035]$} & {$[0.037]$} & {$[0.039]$} & {$[0.037]$} & {$[0.045]$} & {$[0.051]$} & {$[0.055]^{*}$} & {$[0.057]$} & {$[0.076]$} & {$[0.084]$} & [0.091] \\
\hline Head is white & 0.192 & 0.163 & 0.158 & 0.082 & -0.069 & -0.071 & -0.048 & 0.009 & -0.202 & -0.072 & -0.054 & 0.298 \\
\hline
\end{tabular}

Table continued on the next page 


\begin{tabular}{|c|c|c|c|c|c|c|c|c|c|c|c|c|}
\hline & $\mathrm{e} 0$ & e1 & $\mathrm{e} 2$ & e3 & e4 & e5 & e6 & e7 & e8 & e9 & $\mathrm{e} 10$ & $\mathrm{e} 11$ \\
\hline \multirow[t]{2}{*}{$\begin{array}{l}\text { Low occupational } \\
\text { status of the head (1) }\end{array}$} & -0.221 & -0.182 & -0.239 & -0.289 & -0.180 & -0.206 & -0.188 & -0.239 & -0.247 & -0.264 & -0.112 & -0.067 \\
\hline & {$[0.026]^{* *}$} & {$[0.035]^{* *}$} & {$[0.036]^{* *}$} & {$[0.038]^{* *}$} & {$[0.036]^{* *}$} & {$[0.044]^{* *}$} & {$[0.050]^{* *}$} & {$[0.055]^{* *}$} & {$[0.056]^{* *}$} & {$[0.075]^{* *}$} & {$[0.082]$} & {$[0.093]$} \\
\hline \multirow{2}{*}{$\begin{array}{l}\text { High occupational } \\
\text { status of the head (1) }\end{array}$} & -0.275 & -0.216 & -0.189 & -0.241 & -0.227 & -0.118 & -0.078 & -0.089 & -0.164 & -0.129 & -0.031 & -0.055 \\
\hline & {$[0.030]^{* *}$} & {$[0.041]^{* *}$} & {$[0.044]^{* *}$} & {$[0.045]^{* *}$} & {$[0.043]^{* *}$} & {$[0.054]^{*}$} & {$[0.061]$} & {$[0.067]$} & {$[0.067]^{*}$} & {$[0.090]$} & {$[0.098]$} & [0.104] \\
\hline Number of siblings & $\begin{array}{r}-0.044 \\
{[0.004]^{* *}}\end{array}$ & -0.043 & $\begin{array}{r}-0.042 \\
{[0.006]^{* *}}\end{array}$ & $\begin{array}{r}-0.048 \\
{[0.006]^{* *}}\end{array}$ & $\begin{array}{r}-0.065 \\
{[0.006]^{* *}}\end{array}$ & $\begin{array}{r}-0.078 \\
{[0.008]^{* *}}\end{array}$ & $\begin{array}{r}-0.065 \\
{[0.009]^{* *}}\end{array}$ & $\begin{array}{r}-0.052 \\
{[0.010]^{* *}}\end{array}$ & $\begin{array}{r}-0.072 \\
{[0.011]^{* *}}\end{array}$ & $\begin{array}{r}-0.071 \\
{[0.014]^{* *}}\end{array}$ & $\begin{array}{r}-0.058 \\
{[0.017]^{* *}}\end{array}$ & $\begin{array}{r}-0.108 \\
{[0.020]^{* *}}\end{array}$ \\
\hline Constant & $\begin{array}{r}0.491 \\
{[0.036]^{* *}}\end{array}$ & $\begin{array}{r}1.356 \\
{[0.049]^{* *}}\end{array}$ & $\begin{array}{r}1.280 \\
{[0.053]^{* *}}\end{array}$ & $\begin{array}{r}0.992 \\
{[0.056]^{* *}}\end{array}$ & $\begin{array}{r}0.020 \\
{[0.055]}\end{array}$ & $\begin{array}{r}0.897 \\
{[0.073]^{* *}}\end{array}$ & $\begin{array}{r}1.064 \\
{[0.088]^{* *}}\end{array}$ & $\begin{array}{r}0.916 \\
{[0.100]^{* *}}\end{array}$ & $\begin{array}{r}0.589 \\
{[0.107]^{* *}}\end{array}$ & $\begin{array}{r}1.115 \\
{[0.150]^{* *}}\end{array}$ & $\begin{array}{r}1.150 \\
{[0.170]^{* *}}\end{array}$ & $\begin{array}{r}-1.712 \\
{[0.210]^{* *}}\end{array}$ \\
\hline Observations & 94003 & 71035 & 60257 & 50470 & 41214 & 29823 & 22969 & 18005 & 13882 & 9440 & 7184 & 5233 \\
\hline Chi-square statistics & 5242 & 1183 & 916 & 1194 & 2394 & 642 & 326 & 260 & 268 & 97 & 50 & 223 \\
\hline Pseudo R2 & 0.08 & 0.03 & 0.02 & 0.03 & 0.07 & 0.03 & 0.02 & 0.02 & 0.02 & 0.01 & 0.01 & 0.05 \\
\hline
\end{tabular}

Note: (1) Omitted category: no occupation status of the head

Degrees of freedom $=10$

Robust standard errors in brackets

* significant at $5 \%$; * significant at $1 \%$ 
Table A.2:

Results for the school transition model: 1999

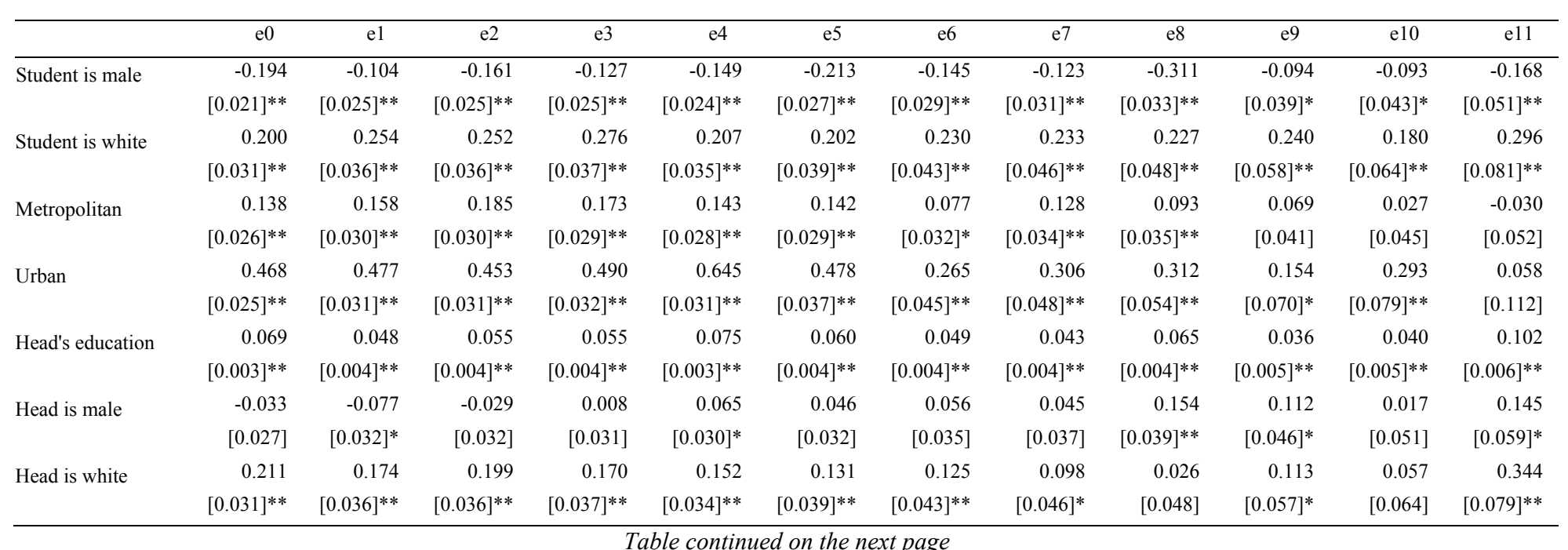




\begin{tabular}{|c|c|c|c|c|c|c|c|c|c|c|c|c|}
\hline \multicolumn{13}{|c|}{ Table A.2 (continued) } \\
\hline & $\mathrm{e} 0$ & e1 & $\mathrm{e} 2$ & $\mathrm{e} 3$ & $\mathrm{e} 4$ & $\mathrm{e} 5$ & e6 & e7 & e8 & e9 & $\mathrm{e} 10$ & e11 \\
\hline \multirow{2}{*}{$\begin{array}{l}\text { Low occupational } \\
\text { status of the head (1) }\end{array}$} & -0.224 & -0.358 & -0.307 & -0.284 & -0.257 & -0.333 & -0.371 & -0.41 & -0.371 & -0.465 & -0.332 & -0.459 \\
\hline & {$[0.030] * *$} & {$[0.037]^{* *}$} & {$[0.036]^{* *}$} & {$[0.036]^{* *}$} & {$[0.034]^{* *}$} & {$[0.037]^{* *}$} & {$[0.041]^{* *}$} & {$[0.043]^{* *}$} & {$[0.044]^{* *}$} & {$[0.052]^{* *}$} & {$[0.057]^{* *}$} & {$[0.069]^{* *}$} \\
\hline \multirow{2}{*}{$\begin{array}{l}\text { High occupational } \\
\text { status of the head (1) }\end{array}$} & -0.141 & -0.333 & -0.296 & -0.230 & -0.187 & -0.169 & -0.228 & -0.240 & -0.202 & -0.250 & -0.106 & -0.002 \\
\hline & {$[0.036]^{* *}$} & {$[0.042]^{* *}$} & {$[0.042]^{* *}$} & {$[0.042]^{* *}$} & {$[0.040]^{* *}$} & {$[0.044]^{* *}$} & {$[0.048]^{* *}$} & {$[0.049]^{* *}$} & {$[0.051]^{* *}$} & {$[0.060]^{* *}$} & {$[0.064]$} & {$[0.068]$} \\
\hline \multirow[t]{2}{*}{ Number of siblings } & -0.028 & -0.031 & -0.033 & -0.027 & -0.041 & -0.025 & -0.025 & -0.016 & -0.019 & -0.019 & -0.027 & -0.037 \\
\hline & {$[0.004]^{* *}$} & {$[0.004]^{* *}$} & {$[0.004]^{* *}$} & {$[0.005]^{* *}$} & {$[0.004]^{* *}$} & {$[0.005]^{* *}$} & {$[0.006]^{* *}$} & {$[0.006]^{* *}$} & {$[0.007]^{* *}$} & {$[0.008]^{*}$} & {$[0.009]^{* *}$} & {$[0.012]^{* *}$} \\
\hline \multirow[t]{2}{*}{ Constant } & 1.488 & 1.904 & 1.656 & 1.328 & 0.758 & 0.950 & 1.163 & 0.945 & 0.543 & 0.872 & 0.557 & -1.916 \\
\hline & {$[0.042]^{* *}$} & {$[0.051]^{* *}$} & {$[0.050]^{* *}$} & {$[0.050]^{* *}$} & {$[0.048]^{* *}$} & {$[0.055]^{* *}$} & {$[0.063]^{* *}$} & {$[0.067]^{* *}$} & {$[0.073]^{* *}$} & {$[0.091]^{* *}$} & {$[0.102]^{* *}$} & {$[0.140]^{* *}$} \\
\hline Observations & 102241 & 88732 & 79316 & 69800 & 60049 & 49000 & 39787 & 32374 & 25519 & 18771 & 14053 & 10021 \\
\hline Chi-square statistics & 2291 & 1511 & 1581 & 1514 & 2123 & 1209 & 704 & 583 & 745 & 320 & 245 & 678 \\
\hline Pseudo R2 & 0.040 & 0.030 & 0.040 & 0.040 & 0.050 & 0.030 & 0.020 & 0.020 & 0.030 & 0.020 & 0.020 & 0.080 \\
\hline
\end{tabular}

Notes: (1) Omitted category: non-occupation status of the head

Robust standard errors in brackets

* significant at $5 \%$;* significant at $1 \%$ 
Table A.3:

Results for the school transition model: 2008

\begin{tabular}{|c|c|c|c|c|c|c|c|c|c|c|c|c|}
\hline & $\mathrm{e} 0$ & e1 & e2 & e3 & e4 & e5 & e6 & e7 & $\mathrm{e} 8$ & e9 & $\mathrm{e} 10$ & e11 \\
\hline \multirow[t]{2}{*}{ Student is male } & -0.081 & -0.063 & -0.058 & -0.131 & -0.135 & -0.190 & -0.171 & -0.109 & -0.302 & -0.118 & -0.081 & -0.416 \\
\hline & {$[0.023]^{* *}$} & {$[0.028]^{*}$} & {$[0.028]^{*}$} & {$[0.028]^{* *}$} & {$[0.026]^{* *}$} & {$[0.028]^{* *}$} & {$[0.030]^{* *}$} & {$[0.031]^{* *}$} & {$[0.030]^{* *}$} & {$[0.034]^{* *}$} & {$[0.037]^{*}$} & {$[0.039]^{* *}$} \\
\hline \multirow[t]{2}{*}{ Student is white } & 0.009 & 0.059 & 0.075 & 0.173 & 0.156 & 0.203 & 0.195 & 0.246 & 0.191 & 0.199 & 0.173 & 0.428 \\
\hline & {$[0.028]$} & {$[0.035]$} & {$[0.035]^{*}$} & {$[0.035]^{* *}$} & {$[0.033]^{* *}$} & {$[0.035]^{* *}$} & {$[0.038]^{* *}$} & {$[0.040]^{* *}$} & {$[0.037]^{* *}$} & {$[0.044]^{* *}$} & {$[0.046]^{* *}$} & {$[0.048]^{* *}$} \\
\hline \multirow[t]{2}{*}{ Metropolitan } & 0.019 & 0.093 & 0.102 & 0.043 & 0.144 & 0.087 & 0.143 & 0.179 & 0.089 & 0.162 & 0.127 & -0.033 \\
\hline & {$[0.027]$} & {$[0.033]^{* *}$} & {$[0.032]^{* *}$} & {$[0.032]$} & {$[0.031]^{* *}$} & {$[0.031]^{* *}$} & {$[0.034]^{* *}$} & {$[0.035]^{* *}$} & {$[0.033]^{* *}$} & {$[0.038]^{* *}$} & {$[0.040]^{* *}$} & {$[0.040]$} \\
\hline \multirow[t]{2}{*}{ Head's education } & 0.025 & 0.013 & 0.025 & 0.037 & 0.046 & 0.041 & 0.033 & 0.036 & 0.054 & 0.030 & 0.029 & 0.135 \\
\hline & {$[0.003]^{* *}$} & {$[0.004]^{* *}$} & {$[0.004]^{* *}$} & {$[0.004]^{* *}$} & {$[0.003]^{* *}$} & {$[0.004]^{* *}$} & {$[0.004]^{* *}$} & {$[0.004]^{* *}$} & {$[0.004]^{* *}$} & {$[0.004]^{* *}$} & {$[0.005]^{* *}$} & {$[0.005]^{* *}$} \\
\hline \multirow[t]{2}{*}{ Head is male } & -0.065 & -0.134 & -0.035 & -0.048 & -0.029 & 0.044 & 0.072 & 0.081 & 0.167 & 0.039 & 0.038 & 0.342 \\
\hline & {$[0.025]^{* *}$} & {$[0.032]^{* *}$} & {$[0.031]$} & {$[0.031]$} & {$[0.029]$} & {$[0.030]$} & {$[0.033]^{*}$} & {$[0.033]^{*}$} & {$[0.032]^{* *}$} & {$[0.037]$} & {$[0.039]$} & {$[0.042]^{* *}$} \\
\hline Head is white & 0.188 & 0.191 & 0.138 & 0.106 & 0.148 & 0.104 & 0.055 & 0.160 & 0.093 & 0.097 & 0.069 & 0.165 \\
\hline
\end{tabular}




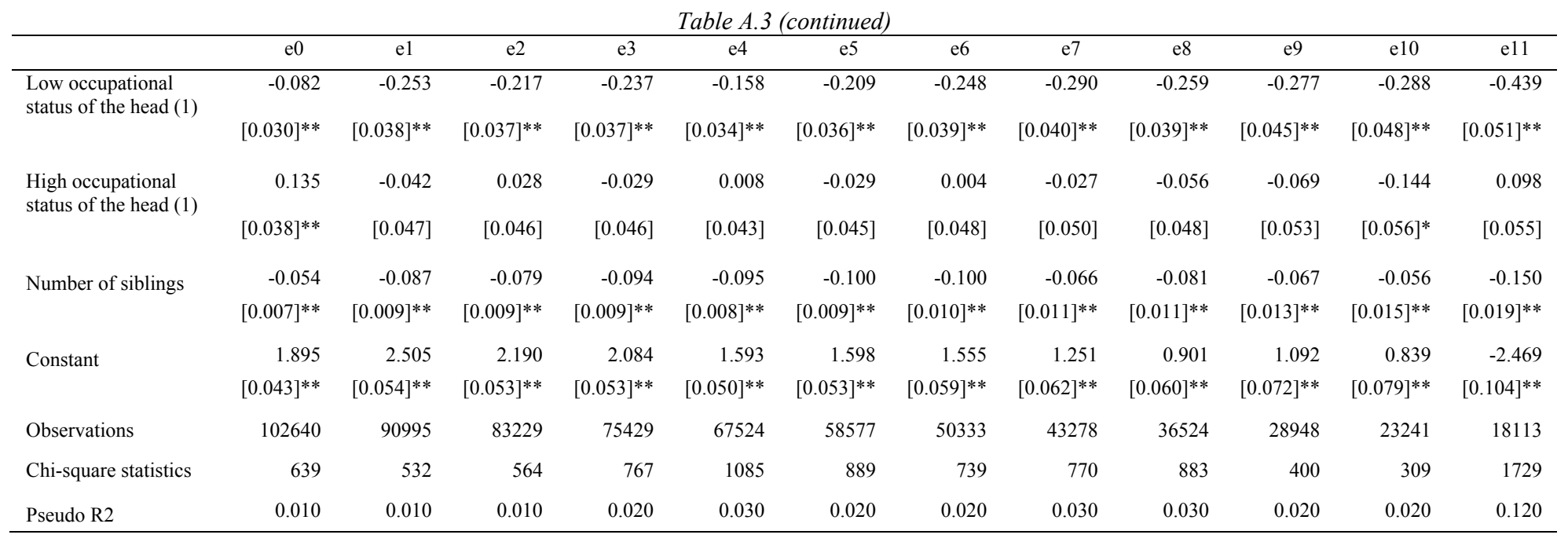

Note: (1) Omitted category: no occupation status of the head

Degrees of freedom $=10$

Robust standard errors in brackets

* significant at $5 \%$;* significant at $1 \%$ 